\title{
CRONICA 2015 DE LA CORTE SUPREMA DE JUSTICIA ARGENTINA
}

\section{Argentina Supreme Court of Justice. Report 2015}

\author{
SERGIO DÍAZ RICCI' \\ Universidad Nacional de Tucumán \\ serdiricci@arnet.com.ar
}

Cómo citar/Citation

Díaz Ricci, S. (2016).

Crónica 2015 de la Corte Suprema de Justicia argentina. Anuario Iberoamericano de Justicia Constitucional, 20, 405-432.

doi: http://dx.doi.org/10.18042/cepc/aijc.20.14

\section{SUMARIO}

I. PANORAMA GENERAL. II. DERECHOS FUNDAMENTALES: 1. Derecho a la vida; 2. Derecho a la Salud. Acción de clase; 3. Derecho a la fertilización asistida; 4. Derecho de acceso a información pública. III. CONFLICTOS INSTITUCIONALES: 1. Jueces subrogantes: 1.1. Conjueces de la Corte Suprema; 1.2. Jueces subrogantes; 2. La Corte fortalece el rol de tribunal constitucional; 3. Primarias Abiertas Simultáneas Obligatorias (PASO). IV. CONFLICTOS CON ESTADOS PROVINCIALES: 1. Coparticipación impositiva Federal; 2. Control de reforma constitucional provincial.

\section{PANORAMA GENERAL}

Esta crónica, como siempre, tiene el propósito de hacer una reseña de la jurisprudencia constitucional argentina mas relevante durante el año 2015,

1 Catedrático de Derecho Constitucional, Universidad Nacional de Tucumán, Universidad San Pablo-Tucumán. 
circunscrita a las sentencias que haya dictado la Corte Suprema de Justicia de Argentina (en adelante, CSJA) como máximo y último tribunal del sistema del control jurisdiccional de la Constitución federal argentina.

Consideramos conveniente recordar dos notas típicas para plantear una cuestión de constitucionalidad en el sistema argentino: por un lado, como regla general la acción debe interponerse ante un juez de primera instancia (control difuso con alcance inter partes) y, por otro, solo se admiten cuatro vías para llegar a un pronunciamiento judicial: acción de amparo, habeas corpus, acción declarativa de constitucionalidad y excepción o incidente de constitucionalidad en un juicio común.

Por tanto, los casos que vamos citar aquí son decisiones («fallos», en la jerga argentina) dictadas por la CSJA que llegan a su conocimiento por vía de recurso extraordinario contra sentencias originadas en cualquiera de los cuatro procesos arriba indicados. Estas, por tratarse de pronunciamientos cimeros, tienen indudable trascendencia constitucional. Excepcionalmente (solo en dos casos) puede intervenir la CSJA de manera directa como tribunal de única instancia, pero siempre debe emplearse cualquiera de las cuatro vías antes señaladas.

El año 2015 se inicia con una composición incompleta de la CSJA, de solo cuatro miembros (Lorenzetti, Highton de Nolasco, Maqueda y Fayt), por haber renunciado a fin del año 2014, Eugenio Zaffaroni. El 11 de diciembre de 2015 se hace efectivo el alejamiento de Carlos Fayt, el miembro mas antiguo (había sido nombrado por el presidente Raúl Alfonsin en 1983), quien había presentado su renuncia el 15 de septiembre anterior. En decir, el cuerpo funcionó con cuatro miembros durante casi todo el año $2015^{2}$. La tensión entre el Poder Ejecutivo y la Corte Suprema que se inició con la reforma judicial de 2013, continuó en el año 2015 a través del reiterado intento del Poder Ejecutivo de cubrir las vacantes en el máximo tribunal y de otros tribunales ${ }^{3}$ y del cuestionamiento sobre Carlos Fayt ${ }^{4}$ de 97 años de edad, con la iniciación de un proceso de destitución por juicio político en la

2 En el sistema argentino de designación de miembros de la CSJA — semejante al de Estados Unidos - el presidente presenta una propuesta al Senado. Si recibe el acuerdo del Senado con 2/3 de votos, el presidente procede a su designación.

3 En el año 2015 la presidenta Fernandez de Kirchner presentó tres pliegos para ministro en el Senado que no tuvieron concreción: en abril propuso a Roberto Carlés para cubrir la vacante de Zaffaroni, que fue luego retirada. Luego, al presentar su renuncia Fayt, la presidenta retiró en octubre el pliego de Carlés y propuso otros dos nombres: Domingo Sesin y Eugenio Sarrabayrouse para cubrir las vacantes de Zaffaroni y de Fayt. Estas propuestas no tuvieron curso y fueron retiradas cuando Macri asumió la presidencia en diciembre.

4 Recordemos que este miembro de la Corte había impulsado la declaración de invalidez de la disposición constitucional introducida por la reforma constitucional de 
Cámara de Diputados 5 . Fue un año marcado por la agenda electoral como telón de fondo por las elecciones generales, presidenciales y de renovación de diputados y senadores nacionales, y de gobernadores en todas las provincias. El 9 de agosto hubo primarias abiertas simultáneas obligatorias (PASO) en las que compitieron las distintas agrupaciones para definir sus candidatos a presidente y vicepresidente, a diputados nacionales, a senadores nacionales en las ocho provincias que correspondía renovación, y a parlamentarios del Mercosur $^{6}$. El 25 de octubre fueron las elecciones generales. Sin embargo, hubo una segunda vuelta electoral para el cargo de presidente y vicepresidente porque ninguno de los candidatos obtuvo la mayoría requerida por la Constitución. Finalmente, el 22 de noviembre se realizó el balotaje entre los dos candidatos presidenciales mas votados, Scioli y Macri, resultando electo Mauricio Macri, quien asumió el cargo de presidente el 10 de diciembre. El 15 de diciembre el nuevo presidente, retiró los pliegos de Sesin y Sarrabayrouse que habían sido presentados en octubre por la presidenta Fernández y se hallaban pendientes de tratamiento por el Senado, y los reemplazó por otros nombres: Horacio Rosatti y Carlos Rosenkrantz ${ }^{7}$.

Dos temas ocuparon la escena judicial-constitucional durante el año 2015: el primero, la cuestión de los «jueces subrogantes» nombrados para cubrir transitoriamente el cargo de un juzgado vacante (encontrándose pendiente o no el proceso de cobertura en el Consejo de la Magistratura, por lo que se trata de un asunto que se enmarca en el conflicto desatado en 2013 por la reforma judicial promovida por el Poder Ejecutivo) y el reclamo de tres provincias contra la Nación por apropiación indebida de recursos fiscales.

1994, que había limitado a 75 años la edad para los jueces, con posibilidad de renovar a través de un nuevo nombramiento (Caso Fayt, de 1999, Fallos 322 II:1616).

5 En septiembre de 2015, Fayt presentó su renuncia al cargo, posponiendo su operatividad para el 11 de diciembre, un día después de la asunción del nuevo presidente Macri. A partir de entonces el máximo tribunal redujo su composición a tres integrantes.

6 Por primera vez, Argentina procedía a la elección popular de 43 parlamentarios para el Parlamento del Mercosur (Parlasur): 19 en distrito único y 24 a razón de uno por provincia y la CABA.

7 En un primer momento, en diciembre 2015, el presidente Macri dispuso directamente el nombramiento de estos dos candidatos a través de un decreto de necesidad y urgencia, basándose en que el Congreso se hallaba en receso. Sin embargo, luego aceptó que se siguiese el procedimiento regular que para estos nombramientos prevé la Constitución (acuerdo previo del Senado). 


\section{DERECHOS FUNDAMENTALES}

\section{DERECHO A LA VIDA}

(D., M. A., sentencia de declaración de incapacidad). Fallos 338-1: 556

Un caso muy dramático llegó a la CSJA relacionado con la petición de dos hermanas para que se ponga fin a la asistencia médica que mantenía desde 20 años con vida a una persona en estado vegetativo persistente e irreversible, originado en un accidente automovilístico ocurrido en el año 1994 que le ocasionó un traumatismo encéfalo-craneano severo con pérdida del conocimiento, politraumatismos graves y epilepsia postraumática.

El Caso D., M. A. Sentencia declaración de incapacidad, se inicia con el pedido de sus hermanas, únicas familiares cercanas a este hombre soltero, a un tribunal de primera instancia de la provincia de Neuquén para que se ordenara el retiro, cese y abstención de la hidratación y la alimentación enteral, así como de todas las medidas de sostén vital que lo mantienen con vida en forma artificial.

El juez de primera instancia rechazó la petición. Esta sentencia fue apelada y resultó confirmada por el tribunal de alzada. Finalmente, el caso llegó al Tribunal Superior de Justicia de esta provincia patagónica, que revocó la sentencia por entender que esta medida estaba habilitada por hallarse comprendida en la Ley de Derechos del Paciente en su Relación con los Profesionales e Instituciones de la Salud (Ley 26 529, modificada por la ley 26742 ) por lo que no resultaba necesario que las representantes de M. A. D. requieran autorización judicial alguna, y declaró que la petición debe tramitarse conforme al procedimiento fijado en la ley sin necesidad de intervención judicial.

Contra este pronunciamiento el curador ad litem y el representante del Ministerio Público de Incapaces de la provincia interpusieron sendos recursos extraordinarios a la CSJA por considerar que la decisión del Tribunal Superior de Neuquén constituye una sentencia arbitraria. Sostienen que el paciente no padece una enfermedad terminal y no enfrenta una situación de muerte inminente, como es la hipótesis que contempla la ley nacional, sino un estado de salud estable por fase vegetativa permanente, que solo necesita para vivir hidratación y alimentación, sin requerir mecanismo alguno artificial respiratorio o de otra índole. La hidratación y la alimentación no configuran procedimientos extraordinarios o desproporcionados, sino necesidades básicas de todo ser viviente. Por tanto, en este caso el retiro peticionado habilitaría una muerte por deshidratación e inanición, o sea, una práctica eutanásica prohibida por la ley. Además, el derecho a morir con dignidad es inherente a la persona y, como tal, solo puede ser ejercido por su titular, lo que en este caso 
no es posible porque el paciente no expresó su voluntad respecto al retiro del soporte vital, como lo exige la ley.

La CSJA abrió el recurso extraordinario por entender que había cuestión federal suficiente por hallarse comprometidos el derecho a la vida, a la autonomía personal, a la dignidad humana y a la intimidad

A fin de contar con una opinión médica, la CSJA realizó entre abril de 2014 y febrero de 2015 una serie de consultas con el objeto de reunir la mayor cantidad de información científica posible y actualizada para decidir un caso de tal trascendencia, llegándose a hacer evaluaciones directas del paciente a cargo de los forenses de la CSJA y del Instituto de Neurociencias de la Fundación Favaloro.

De los estudios médicos se desprende que el estado del paciente no se mantuvo estable, sino que sufrió numerosas crisis que motivaron una serie de intervenciones quirúrgicas y médicas, y queda catalogado como "estado de mínima conciencia» (EMC) permanente sin cambios durante más de dos décadas. En consecuencia, se trata de un caso que excede todo indicador conocido de la estadística médica.

En suma, en razón de tratarse de un paciente desahuciado en estado terminal, incurable e irreversible, la CSJA entendió que el caso se encuadra en las previsiones de la ley en cuestión, que admite la solicitud para que cesen los procedimientos de hidratación y alimentación artificial. Los informes médicos y los dictámenes del Comité de Ética coinciden en que la retirada de los procedimientos de hidratación y alimentación artificial pueden ser asimilados a tratamientos médicos, por lo que pueden ser objeto de renuncia por parte de pacientes terminales.

El quid jurídico aquí reside en que el paciente se encuentra sin conciencia para manifestar su voluntad, situación no prevista por la ley, que contempla solo el supuesto de que el paciente emita un declaración suficiente de voluntad que manifieste claramente un consentimiento informado (luego de recibir, por parte del profesional interviniente, información clara, precisa y adecuada) de su derecho a aceptar o rechazar, con o sin expresión de causa, determinadas terapias o procedimientos médicos o biológicos, quirúrgicos, de hidratación, alimentación, de reanimación artificial, o al retiro de medidas de soporte vital en caso de padecer una enfermedad irreversible, incurable o cuando se encuentre en estado terminal, o cuando sean extraordinarios o desproporcionados en relación con las perspectivas de mejoría, o que produzcan sufrimiento desmesurado, y de su derecho a rechazar procedimientos de hidratación y alimentación cuando los mismos produzcan como único efecto la prolongación en el tiempo de ese estadio terminal irreversible e incurable (Ley 26 529, art. 5 inc. g). 
La CSJA acude a jurisprudencia internacional en peticiones análogas para pacientes que carecían de conciencia de sí mismo y del mundo exterior y cuyo estado resultaba también irreversible (Suprema Corte de los Estados Unidos, Cruzan v. Director Missouri Departament of Health, 497 U. S. 261, Sentencia del 25 de junio de 1990; Cámara de los Lores del Reino Unido, Airedale NHS Trust $v$. Bland, 1 All ER 821, Sentencia del 4 de febrero de 1993; Corte Suprema de Casación de Italia, Sección Primera Civil, Sentencia 21 748/07 del 16 de octubre de 2007, caso Englaro; Consejo de Estado Francés, Mme. F. I. et autres, Sentencia del 24 de junio de 2014). En especial cita la Guía del Consejo de Europa para el proceso de toma de decisiones relativas al tratamiento médico en situaciones del final de la vida, y la reciente sentencia del Tribunal Europeo de Derechos Humanos que convalidó una decisión del Consejo de Estado francés (conf. Lambert y otros $v$. Francia, Fallo del 5 de junio de 2015).

El caso se trata de un paciente mayor de edad que hace más de 20 años se encuentra internado sin conciencia de sí mismo ni del mundo que lo rodea y que, además, no ha brindado ninguna directiva anticipada formalizada por escrito respecto a qué conducta médica debe adoptarse con relación a la situación en la que se halla actualmente (lo que era fáctica y legalmente imposible). En consecuencia, no puede ahora ni podrá en el futuro declarar por sí mismo la decisión relativa a la continuidad del tratamiento médico y del soporte vital que viene recibiendo desde el año 1994. La CSJA se formula la pregunta de si es posible conocer cuál es la voluntad de paciente respecto a esta cuestión.

Comienza por una aseveración: la decisión de aceptar o rechazar un tratamiento médico constituye un ejercicio de la autodeterminación que asiste a toda persona por imperio constitucional, que halla su fundamento en el art. 19 CA. Seguidamente, advierte que la ley 26529 prevé la situación de los pacientes que, como en este caso, se encuentran incapacitados o imposibilitados de expresar su consentimiento informado a causa de su estado físico o psíquico. Para estos casos, se aplica la Ley 24193 sobre Trasplante de Órganos (art. 21) en que el consentimiento del paciente podrá ser dado por familiares según un orden de prelación; entre ellos, los hermanos se encuentran autorizados a dar testimonio de la voluntad del paciente. Concluye que en el sistema establecido por el legislador, determinadas personas vinculadas al paciente -impedido para expresar por sí y en forma plena esta clase de decisión- pueden hacer operativa la voluntad de este y resultan sus interlocutores ante los médicos a la hora de decidir la continuidad del tratamiento o el cese del soporte vital.

La interpretación de la CSJA es al menos sugerente, pues realiza un esfuerzo para encontrar sentido al silencio del paciente, partiendo de un presupuesto: "Que resulta indispensable valorar que las hermanas de M. A. 
D., que son mayores de edad y, a su vez, fueron designadas como sus cuidadoras, solicitaron el cese de la provisión de tratamiento médico y de medidas de soporte vital manifestando con carácter de declaración jurada que esta solicitud responde a la voluntad de su hermano». Para ello, la CSJA hace una pirueta interpretativa: «En este sentido, debe aclararse y resaltarse que por tratarse la vida y la salud de derechos personalísimos, de ningún modo puede considerarse que el legislador haya transferido a las personas indicadas un poder incondicionado para disponer la suerte del paciente mayor de edad que se encuentra en un estado total y permanente de inconsciencia» para concluir forzadamente que "no se trata de que las personas autorizadas por la ley —en el caso, las hermanas de M. A. D.— decidan la cuestión relativa a la continuidad del tratamiento médico o de la provisión de soporte vital de su hermano en función de sus propios valores, principios o preferencias, sino que, como resulta claro del texto del art. 21 de la Ley 24 193, al que remite el art. 6 de la Ley 26 529, ellas solo pueden testimoniar, bajo declaración jurada, en qué consiste la voluntad de aquel a este respecto. Los términos del art. 21 de la ley — continúa — son claros en cuanto a que quienes pueden trasmitir el consentimiento informado del paciente no actúan a partir de sus convicciones propias, sino dando testimonio de la voluntad de este. Es decir, que no deciden ni 'en el lugar' del paciente ni 'por' el paciente, sino comunicando su voluntad». Más adelante, fundándose en la Convención Internacional sobre los Derechos de las Personas con Discapacidad (art. 12) — que en Argentina tiene jerarquía constitucional—, explica su argumentación en estos términos: «Lo que la manifestación de la persona designada por ley debe reflejar es la voluntad de quien se encuentra privado de consciencia y su modo personal de concebir para sí, antes de caer en este estado de inconsciencia permanente e irreversible, su personal e intransferible idea de dignidad humana». Revelando poca convicción va a reiterar que la ley «no autoriza a las personas allí designadas a decidir por sí, y a partir de sus propias valoraciones subjetivas y personales, con relación del tratamiento médico de quien se encuentra impedido de expresarse en forma absoluta y permanente a su respecto. De este modo, lo que la norma exclusivamente les permite es intervenir dando testimonio juramentado de la voluntad del paciente con el objeto de hacerla efectiva y garantizar la autodeterminación de este».

Finalmente, manifiesta una preocupación para futuros casos análogos al considerar que «el legislador no ha exigido que el ejercicio del derecho a aceptar o rechazar las prácticas médicas ya referidas quede supeditado a una autorización judicial previa». De este modo, pretendiendo evitar la intervención judicial (en una solución aplicada al caso F. A. L. de Fallos 335:197), llega a afirmar que «no debe exigirse una autorización judicial para convalidar 
las decisiones tomadas por los pacientes respecto de la continuidad de los tratamientos médicos, en la medida en que estas se ajusten a los supuestos y requisitos establecidos en la ley». Este camino elusivo resultará ineficaz porque no puede soslayarse ni impedirse nunca el derecho de "acceso a las justicia» porque, además, no puede delegarse el personal médico que deba tomar motu proprio tamaña decisión vital, como termina por admitirlo cuando señala «la necesidad de que las autoridades correspondientes contemplen mediante un protocolo las vías por las que el personal sanitario pueda ejercer su derecho de objeción de conciencia sin que ello se traduzca en derivaciones o demoras que comprometan la atención del paciente».

En resumen, la CSJA con fecha 7 de julio de 2015, confirmó la sentencia del Tribunal Superior de Provincia que accedió a la petición de las hermanas de suspender el tratamiento de hidratación y alimentación enteral, con una nota aditamento dramático: la orden no se llegó a cumplir porque ese mismo día se produjo el deceso de esa persona.

\section{DERECHO A LA SALUD. ACCIÓN DE CLASE}

\section{Caso Asociación Civil para la Defensa en el Ámbito Federal e Internacional de Derechos - Asociación DEFEINDER - y asociación civil Pequeña Obra de la Divina Providencia v. Instituto Nacional de Servicios Sociales para Jubilados y Pensionados, sentencia de amparo. Fallos 338-1: 29}

Dos asociaciones civiles que agrupan personas discapacitadas afiliadas a una obra social que atiende a jubilados y pensionados (INSSJP) inician acción de amparo con el objeto de que se reconociera el derecho a la cobertura integral de prestaciones en favor de las personas con discapacidad beneficiarias de pensiones no contributivas.

El juez de primera instancia y la cámara de apelaciones rechazaron el amparo entendiendo que el conflicto motivado por la falta de prestaciones médicas se originaba en el vínculo entre la obra social y los prestadores del servicio, siendo ajeno a los derechos subjetivos de los beneficiarios afectados. Interpuesto el recurso extraordinario, la Cámara lo deniega, lo que genera una queja ante la CSJA, quien decide abrir el recurso por estar en cuestión la legitimación de estas asociaciones para interponer un amparo y la decisión impugnada constituye una sentencia definitiva contraria a las pretensiones de los «amparistas».

Comienza la CSJA por definir que el amparo promovido por las asociaciones demandantes se refiere a intereses individuales homogéneos afectados por el obrar del INSSJP, que obstaculizaría el acceso igualitario a prestaciones integrales de salud a una pluralidad indeterminada de niños, jóvenes y adul- 
tos con discapacidad, titulares de pensiones no contributivas. Seguidamente recuerda que el amparo es la vía judicial de protección de esta categoría de derechos de incidencia colectiva en virtud del segundo párrafo art. $43 \mathrm{CA}$, y conforme a su interpretación dada en los casos Halabi (2009), PADEC $v$. Swiss Medical S. A., Sentencia nulidad de cláusulas contractuales (2013), y Unión de Usuarios y Consumidores $v$. Telefónica de Argentina S. A., Sentencia sumarísimo (2014). Además, indica que la ausencia de una norma que regule en forma precisa y acabada el efectivo ejercicio de las acciones colectivas no puede dejar sin protección a derechos fundamentales consagrados en el texto constitucional.

El ejercicio individual de derechos cede su lugar a las acciones colectivas cuando se verifica una causa fáctica común, una pretensión procesal enfocada en el aspecto colectivo de los efectos del hecho y la constatación de que el interés individual considerado aisladamente no justifique la promoción de una demanda. Y también, cuando, pese a tratarse de derechos individuales, existe un fuerte interés estatal en su protección, sea por su trascendencia social o en virtud de las particulares características de los sectores afectados.

Precisamente, en este caso se persigue la protección de derechos individuales de una pluralidad relevante de sujetos, existe una conducta única y continuada que lesiona a ese colectivo y la pretensión se encuentra enfocada a los efectos comunes del problema, que se vincula directamente con el derecho a la salud. Es decir, se presenta una homogeneidad fáctica y normativa que hace razonable la promoción de la presente demanda en defensa de los intereses de todos los afectados y justifica el dictado de un pronunciamiento único con efectos expansivos a todo el colectivo involucrado. Refuerza esta conclusión el incuestionable contenido social del derecho involucrado que atañe a grupos que por mandato constitucional deben ser objeto de preferente tutela por su condición de vulnerabilidad: los niños, las mujeres, los ancianos y las personas con discapacidad (art. 75, inc. 23 CA).

En conclusión, la CSJA termina por reconocer legitimación a las asociaciones actoras para iniciar la presente acción colectiva a los efectos de garantizar el derecho a la tutela judicial efectiva de un colectivo altamente vulnerable, no solo por la discapacidad que padecen sus integrantes, sino también por su delicada situación socioeconómica, subrayando que la pretensión procesal deducida procura garantizar el acceso, en tiempo y forma, a prestaciones de salud relacionadas con la vida y la integridad física de las personas, cuya protección constituyen necesidades básicas y elementales a cargo del Estado, es decir, involucra un fuerte interés estatal entendido como el de la sociedad en su conjunto ( $c f$. art. 9 del Pacto Internacional de Derechos Económicos, Sociales y Culturales). 


\section{DERECHO A LA FERTILIZACIÓN ASISTIDA}

Recurso de hecho deducido por los actores en la causa L. E. H. y otros v. O. S. E. P., sentencia de amparo. Fallos 338-2: 779

Llegó a conocimiento de la CSJA, por vía de recurso extraordinario contra una sentencia del Superior Tribunal de Justicia de la provincia de Mendoza una acción de amparo interpuesta por una pareja contra una obra social a fin de que esta provea el diagnóstico genético preimplantacional (DGP) como parte del procedimiento de fertilización asistida in vitro (FIV).

Conviene hacer una somera descripción de las etapas procesales que llevaron a la intervención de la CSJA en un caso típico que permite conocer el itinerario del control de constitucionalidad difuso vigente en Argentina. Se inicia con una demanda de amparo interpuesta por particulares ante un juez de primera instancia provincial. Este dicta sentencia rechazando el amparo. Esta sentencia fue apelada ante un Tribunal de Segunda Instancia de esa provincia, que confirmó la sentencia de rechazo del juez a quo. Contra esta decisión de alzada la actora interpuso recurso de inconstitucionalidad ante la Suprema Corte de Justicia de la Provincia de Mendoza, quien confirmó la sentencia de rechazo del amparo. Contra esta última decisión la actora interpuso ante el mismo Superior Tribunal de Justicia local un recurso extraordinario ante la CSJA, el que fue rechazado por dicho Superior Tribunal provincial. Esta denegatoria motivó la presentación directa en Buenos Airesr ante la CSJA de un recurso de queja. La Corte argentina abrió el recurso directo por entender que había un derecho federal en crisis (y la decisión había sido en contra de este derecho federal invocado), aunque finalmente confirmó las sentencias dictadas en la órbita provincial de rechazo del amparo.

Los actores invocaban, cual derecho constitucional que debía ser tutelado por vía de amparo, contar con el derecho humano de acceso integral a las técnicas de reproducción humana asistida en los términos desarrollados por la Corte Interamericana de Derechos Humanos (CIDH) en la causa Artavia Murillo $v$. Costa Rica (2012).

La CSJA recordará que el derecho a la salud, íntimamente relacionado con el derecho a la vida (Fallos 329:2552; 333:690, entre otros) y del cual forma parte el derecho a la salud reproductiva «deben ser ejercidos con arreglo a las leyes que reglamentan su ejercicio, en la forma y extensión que el Congreso lo estime conveniente a fin de asegurar el bienestar general (arts. 14 y $28 \mathrm{CA}$ ), con la única condición de no ser alterados en su substancia» (Wesensgehalt). Consecuentemente, la ley 26862 dispuso el derecho al acceso integral a los procedimientos y técnicas médico-asistenciales de reproducción asistida, que 
deben ser proporcionadas por las obras sociales como parte del Programa Médico Obligatorio (PMO).

Sin embargo, el DGP que reclaman los actores, no está incluido en la ley dentro de las técnicas y procedimientos enumerados como integrantes de la cobertura que los prestadores de servicios de salud deben proporcionar con carácter obligatorio, como tampoco en el decreto reglamentario de esa norma legal, que omite toda referencia al DGP.

Si bien la reglamentación legal deja abierta la posibilidad de agregar nuevos procedimientos y técnicas desarrollados mediante avances técnico-científicos, estos necesitan ser autorizados por la autoridad de aplicación, lo que no ha ocurrido con la técnica DGP. La ley ha conferido al Ministerio de Salud de la nación esta atribución en razón en la especificidad de las facultades, competencias, técnicas y responsabilidades en materia de salud que compete esta cartera ministerial, «de las que carecen, en principio, las estructuras correspondientes a otros departamentos del Estado, entre ellas las del Poder Judicial». Explayándose sobre esto último expresa «que deviene inadmisible que sean los jueces o tribunales - y más aún dentro del limitado marco cognoscitivo que ofrece la acción de amparo- quienes determinen la incorporación al catálogo de procedimientos y técnicas de reproducción humana autorizados, una práctica médica cuya ejecución ha sido resistida en esta causa [...] porque la misión de los jueces es dar pleno efecto a las normas vigentes sin sustituir al legislador ni juzgar sobre el mero acierto o conveniencias de las disposiciones adoptadas por otros poderes en ejercicio de su propias facultades».

Finalmente, concluye, que "cabe descartar que la negativa de la obra social demandada a hacerse cargo del costo de la prestación cuestionada pueda ser considerada un acto u omisión teñido de arbitrariedad o ilegalidad manifiesta $[\ldots]$ en la medida en que no existe una norma específica que le imponga tal obligación». Consecuentemente, «se hace lugar a la queja, se declara procedente el recurso extraordinario y se confirma la sentencia apelada». En suma, se confirma el rechazo del amparo por no hallarse ninguna norma federal comprometida de inconstitucionalidad.

\section{DERECHO DE ACCESO A INFORMACIÓN PÚBLICA}

Caso Giustiniani, Rubén Héctor v. Y. P. F., sentencia de amparo por mora. Fallos 338-2: 1263

Un senador nacional interpuso una acción de amparo con el objeto de que la empresa petrolera nacional (YPF) le entregara copia íntegra del acuerdo de inversión que esta sociedad estatal había suscripto con Chevron Corpora- 
tion para la explotación conjunta de hidrocarburos no convencionales en la provincia del Neuquén.

Tanto el juez de primera instancia como la Cámara de apelaciones denegaron el amparo; sin embargo, la CSJA abrió a su decisión el recurso extraordinario y dictó sentencia el 10/11/2015.

Pivotando sobre la idea que la libertad de información es un derecho humano fundamental, cita en apoyo a instrumentos internacionales tales como la Declaración Americana de Derechos y Deberes del Hombre (art. IV), la Convención Americana sobre Derechos Humanos (art. 13.1d), la Resolución 59 de la Asamblea General de la Organización de las Naciones Unidas, el Pacto Internacional de Derechos Civiles y Políticos de Naciones Unidas (art. 19), el Estudio Especial sobre el Derecho de Acceso a la Información, Relatoría Especial para la Libertad de Expresión, de la Comisión Interamericana de Derechos Humanos de la OEA (agosto de 2007). También la CSJA trajo a colación el caso CIPPEC $v$. EN-M. de Desarrollo Social, Decreto 1172/03, sentencia de amparo ley 16 986» del 26/03/2014 (Fallos: 335:2393), donde apoyándose en el caso Claude Reyes y otros $v$. Chile (19/09/2006), la Corte Interamericana interpreta que «el derecho a la libertad de pensamiento y de expresión contempla la protección del derecho de acceso a la información bajo control del Estado, el cual también contiene de manera clara dos dimensiones: individual y social, del derecho a la libertad de pensamiento y de expresión, las cuales deben ser garantizadas por el Estado de forma simultánea».

La CSJA considera que YPF es uno de los sujetos que, por funcionar bajo la jurisdicción del Poder Ejecutivo nacional, se halla obligado a dar cumplimiento a las disposiciones del Reglamento General de Acceso a la Información Pública (Decreto 1172/03, art. 2, anexo VII), en razón de que el Poder Ejecutivo ejerce autoridad para gobernar dicha sociedad por detentar un rol preponderante en la participación accionaria y en la formación de las decisiones societarias. En consecuencia, YPF integra el sector público nacional, ya que «la empresa desempeña importantes y trascendentes actividades, en las que se encuentra comprometido el interés público, por lo que no puede, en el marco de los principios de una sociedad democrática y de acuerdo a la jurisprudencia reseñada, negar información de indudable interés público, que hace a la transparencia y a la publicidad de su gestión».

Que no obsta para ello la circunstancia que YPF revista forma de una sociedad anónima porque "con el objeto de desarrollar ciertos cometidos públicos, el Estado nacional ha recurrido a la utilización de figuras empresariales o societarias, a las que se exime de las reglas propias de la Administración y somete al derecho privado. Con su utilización se pretende agilizar la obtención de ciertos objetivos, relevando a estas personas jurídicas de algunas limi- 
taciones procedimentales propias de la Administración Pública que podrían obstaculizar su actuación comercial».

Aludiendo al Caso CIPPEC, señala la CSJA que el derecho de acceso a la información — que goza de protección constitucional y convencionalcorresponde a cualquier persona para ejercer el control democrático de las gestiones estatales, de forma tal que puedan cuestionar, indagar y considerar si se está dando un adecuado cumplimiento a las funciones públicas, para aseverar que «la información no pertenece al Estado sino que es del pueblo de la nación argentina» y el Decreto 1172/03 reglamenta «el control democrático, que supone el acceso a la información pública, y que puede realizar cualquier ciudadano para vigilar la marcha de los asuntos de interés general».

Seguidamente, la CSJA pasa a examinar si en el caso hay un supuesto que, de acuerdo con el citado Decreto, permite a los sujetos obligados exceptuarse de proveer la información que les fuera requerida cuando se comprometen secretos industriales, comerciales, financieros, científicos o técnicos. $\mathrm{O}$ sea, para poder limitar el principio de máxima divulgación imperante en la materia, los sujetos obligados para rechazar un requerimiento de información deben exponer, describir y demostrar de manera detallada los elementos y las razones por las cuales su entrega resulta susceptible de ocasionar un daño al fin legítimamente protegido. Pero en este pleito la demandada YPF exclusivamente se limitó a invocar la concurrencia de las causales de excepción contempladas en la normativa sin aportar mayores precisiones cuando corresponde a la parte obligada probar el presupuesto de hecho de la norma o normas que invoca como fundamento de su defensa o excepción. La CSJA, por mayoría, resuelve que «se hace lugar a la queja, se declara procedente el recurso extraordinario, se revoca la sentencia apelada, y se hace lugar a la demanda».

\section{CONFLICTOS INSTITUCIONALES}

\section{JUECES SUBROGANTES}

\subsection{Conjueces de la Corte Suprema}

Causa Aparicio, Ana Beatriz y otros v. Estado Nacional -Corte Suprema de Justicia de la Nación, Consejo de la Magistratura-, sentencia sobre empleo público. Fallos 338-1: 284

Un reclamo de actualización de haberes por depreciación monetaria presentado por un grupo jueces nacionales, dio lugar a un pronunciamiento de 
la CSJA referido al nombramiento de conjueces ad hoc de la propia Corte Suprema argentina.

En la causa Aparicio, Ana Beatriz y otros $v$. Estado Nacional (Corte Suprema de Justicia de la Nación - CSJ—, Consejo de la Magistratura), se declaró la nulidad del decreto presidencial que establecía ese listado de conjueces de la CSJA.

Este asunto, que había llegado a la Corte Suprema por recurso extraordinario al tratarse de un reclamo salarial de magistrados judiciales nacionales, motivó que los miembros de la CSJ se excusaran de intervenir porque la resolución del caso los comprendía personalmente. Por la misma razón, también se excusaron de intervenir los presidentes de las Cámaras federales. En consecuencia, hubo que convocar a conjueces a integrar el Tribunal Supremo, quienes son personas ajenas al Poder Judicial.

A tal efecto, el Poder Ejecutivo nacional había dictado el Decreto 856/14 por el que se designaba como conjueces de la CSJA a una lista de abogados, quienes recibieron acuerdo del Senado a tal efecto.

Contra estas nominaciones la parte actora planeó la nulidad de este listado porque el acuerdo prestado por el Senado nacional no había sido dado por la mayoría de dos tercios de senadores presentes que, según el art. 99 inc. $4^{\circ}$ de la Constitución se exige para los casos de designación normal de miembros de la CSJA, entendiendo que, por paralelismo de formas, los conjueces propuestos debieron recibir un acuerdo por esa misma mayoría calificada. Esta impugnación motivó que la CSJA tenga que pronunciarse previamente sobre la validez constitucional de estas designaciones de conjueces en reemplazo de jueces de la Corte alcanzados por causales de excusación. La CSJA procedió a resolver no el fondo del reclamo salarial, sino a «dilucidar si el proceso que concluyó con el dictado del Decreto 856/2014, de designación de conjueces de la CSJ, se adecuó a las reglas y recaudos establecidos en la Constitución nacional» ante la eventualidad que pueda conducir a una situación de privación de justicia en cualquier otra situación semejante.

El Reglamento para la justicia federal establece que cuando ocurra la excusación de los miembros de la CSJ, estos serán reemplazados por los presidentes de las cámaras de apelaciones federales, y si ocurriese la excusación de estos, el Poder Ejecutivo designará, con acuerdo del Senado, un listado de diez abogados para que actúen como conjueces de la Corte Suprema con una duración de tres años (art. 22 del Decreto ley 1285/58, ratificado por la Ley 14 467). Por su parte, el art. 99 inc. $4^{\circ}$, primer párrafo, establece que corresponde al Poder Ejecutivo nacional nombrar a los magistrados de la CSJ con acuerdo del Senado por el voto de una mayoría de dos tercios de sus miembros presentes, en sesión pública convocada a tal efecto. Entiende la CSJA que se trata de un acto múltiple y complejo que exige la participación 
del Senado porque «el constituyente entendió que, a los efectos de limitar la referida discrecionalidad [del Poder Ejecutivo en la propuesta de magistrados federales], consolidar la independencia del Poder Judicial de la nación y reforzar el equilibrio político que debe primar en la integración del cuerpo, resultaba necesario dar aun más vigor al rol del Senado de la nación en el procedimiento y, en consecuencia, estableció que el acuerdo que dicho cuerpo confiere al candidato propuesto debe contar con el voto de una mayoría calificada, adoptada en sesión pública convocada al efecto». La afirmación de «que el nombramiento de los jueces de la nación con arreglo al sistema constitucionalmente establecido se erige en uno de los pilares esenciales del sistema de división de poderes sobre el que se asienta la República», es corroborada con la cita de pactos internacionales de rango constitucional que fija el «derecho de toda persona a ser oída por un juez o tribunal competente, independiente e imparcial (art. 26 de la Declaración Americana de los Derechos y Deberes del Hombre de 1948; art. 14.1 del Pacto Internacional de Derechos Civiles y Políticos de 1966; art. 8.1 de la Convención Americana sobre Derechos Humanos «Pacto de San José de Costa Rica» de 1969; art. 10 de la Declaración Universal de Derechos Humanos)», y de la Corte Interamericana «cuya jurisprudencia debe servir de guía para la interpretación de los preceptos convencionales de orden internacional (Fallos 321:3555; 328:1491)», para aseverar que el principio de independencia judicial constituye uno de los pilares básicos de las garantías del debido proceso ${ }^{8}$.

Concluye así la CSJA que, por paralelismo de las formas y por voluntad del constituyente reformador de 1994 (que introdujo esta condición expresa para los miembros de la Corte Suprema), estos conjueces debieron recibir el acuerdo del Senado con el voto de las dos terceras partes de sus miembros presentes conforme lo dispone el art. 99 inc. $4^{\circ} \mathrm{CA}$, interpretación que resulta corroborada por el Reglamento del Senado que regula de manera análoga, sin distinción, el procedimiento para el acuerdo de jueces y conjueces.

La circunstancia de la eventualidad y transitoriedad en que estos conjueces ocupen temporalmente el lugar de los miembros titulares de la CSJA, no obsta a que se cumpla esta condición porque aquellos deben desarrollar su función en paridad de condiciones con el juez titular que reemplazan. La provisionalidad no significa una mengua en las garantías previstas para el juez natural.

Finalmente, teniendo a la vista el acta de sesión del Senado que no refleja la mayoría de dos tercios de los presentes, la CSJA procede a «declarar

8 Hace especial referencia a los casos Herrera Ulloa $v$. Costa Rica, sentencia de 2 de julio de 2004; Palamara Iribarne $v$. Chile, sentencia de 31 de enero de 2001; Apitz Barbera y otros (Corte Primera de lo Contencioso Administrativo) $v$. Venezuela, sentencia de 5 de agosto de 2008, y Reverón Trujillo $v$. Venezuela, sentencia de 30 de junio de 2009. 
la nulidad de la designación de conjueces efectuada por el Poder Ejecutivo nacional oficializada en el Decreto 856/14, en tanto el referido acuerdo no contó con el voto de los dos tercios de los miembros presentes del Senado de la Nación»e, implícitamente, ha realizado el control judicial de validez de un acto parlamentario.

\subsection{Jueces subrogantes}

Caso Uriarte, Rodolfo Marcelo y otro v. Consejo de la Magistratura de la Nación, sentencia acción mera declarativa de inconstitucionalidad.

Fallos 338-1: 1229

La validez del nombramiento de jueces subrogantes (interinos) por el Consejo de la Magistratura para cubrir temporalmente cargos vacantes en un tribunal de la jurisdicción nacional, hasta tanto se tramite el concurso final, provocó también tensión institucional.

El Consejo de la Magistratura (CM), de conformidad a la facultad conferida por la ley 24937 (modificada por ley 26 855), en el año 2014 había dictado un «Reglamento de Subrogaciones de los Tribunales Inferiores de la Nación" para regular la designación de jueces subrogantes para los casos de licencia o suspensión del titular, y en casos de vacancia para evitar la suspensión del servicio de justicia en situaciones excepcionales. A tal efecto, la designación debía recaer sobre un secretario judicial elegido por simple mayoría de los 13 miembros del Consejo.

En virtud de este Reglamento, el CM resolvió designar un juez subrogante del Juzgado Federal de Primera Instancia de La Plata, provincia de Buenos Aires, tribunal que, además, tiene competencia electoral en ese importante distrito. Como se podrá suponer, la cuestión no es baladí porque la provincia de Buenos Aires reúne la mayor cantidad de electores en Argentina, con mas de 16 millones de habitantes, y representa el 40\% del padrón electoral, por lo que tiene una influencia decisiva en el resultado en las elecciones presidenciales y parlamentarias del año 2015.

Los presidentes de dos distritos locales de un partido político local plantearon ante un tribunal de primera instancia una acción declarativa de inconstitucionalidad contra esa decisión del CM que había designado a este juez subrogante. El juzgado de primera instancia es quien hizo lugar parcialmente a la demanda. Esta sentencia fue revocada por la Cámara Federal de Apelaciones, lo que dio lugar a un recurso extraordinario ante la CSJA.

El cuestionamiento versaba sobre el nombramiento interino por el CM de jueces subrogantes en un cargo vacante que según el Reglamento debía recaer sobre algún Secretario judicial por decisión tomada por simple mayo- 
ría de los miembros, en forma discrecional, sin sorteo ni parámetro objetivo alguno y sin dar prioridad a los jueces designados mediante el procedimiento constitucional.

La CSJA, en concordancia con un pronunciamiento anterior en relación con estas designaciones interinas (caso Rosza), había señalado que era necesaria la participación de los tres poderes del Estado (CM, el Poder Ejecutivo y el Senado de la nación). La CSJA advierte que de la mera lectura surge que se «autoriza la cobertura de vacancias de magistrados en un proceso en el que no interviene ni el Poder Ejecutivo ni el Senado de la nación. Un mecanismo semejante resulta inconstitucional por no contemplar la necesaria participación de los tres poderes del Estado a los que nuestra Ley Fundamental le encomienda el nombramiento de los jueces». Por tal motivo, se declaró inconstitucional este punto del Reglamento del CM.

Sin embargo, en esta causa surge un nuevo problema. Se había dictado en el ínterin un nuevo texto legal que estableció otro sistema de subrogaciones y fijó un régimen transitorio de designación de subrogantes teniendo en cuenta las pautas fijadas por la CSJA en el caso Rosza (Ley 27145 que vino a reemplazar la anterior la Ley 24 937, modificada por ley 26 855). En virtud de esta última ley, el CM debe elaborar un listado de conjueces que, luego de haber obtenido el acuerdo del Senado, es aprobado por el Poder Ejecutivo; después, producida una vacante, el CM procedía a designar a uno de los integrantes de ese listado como juez subrogante.

Ahora se formulan dos nuevos cuestionamientos: a) el modo en que el $\mathrm{CM}$ elige la persona del listado; b) la forma en que el CM confecciona el listado que luego se va a enviar al Ejecutivo y al Senado.

La primera objeción, o sea, la designación de un conjuez de ese listado para cada caso, quedaba en manos del CM de manera discrecional, sin baremos objetivos que puedan justificar en cada designación la preferencia de un candidato respecto de los restantes. La CSJA concluye que «el Consejo de la Magistratura ejerce, entonces, con absoluta discrecionalidad su atribución de designar jueces subrogantes, pudiendo elegir directamente - a un juez de igual competencia de la misma jurisdicción o a un miembro de la lista de conjueces confeccionada - qué persona quiere para un juzgado o tribunal determinado y también para una causa en particular», en contravención del art. 18 CA que «impone la necesidad de asegurar la transparencia del proceso por el cual se designa a un subrogante en un fuero, en una jurisdicción y en una instancia determinada». Por ello la CSJA invalida esa norma legal que «no resulta admisible porque prevé su selección sin parámetro objetiva alguno. En este esquema, cada designación se justifica en la sola voluntad coincidente de la mayoría no agravada de los miembros del CM de elegir la misma persona. Resulta manifiesto que este método no cumple con la transparencia necesaria 
para garantizar a los justiciables el acceso a jueces subrogantes independientes e imparciales».

También quedó en entredicho la confección de ese listado previo de 40 personas que realiza el CM (20 abogados y 20 secretarios judiciales). El problema reside en que ese listado previo es aprobado por votación de mayoría simple de miembros del CM. Para descalificar esta elección, la CSJA cita un informe de la Comisión Interamericana de Derechos Humanos sobre Garantías para la independencia de las y los operadores de justicia. Hacia el fortalecimiento del acceso a la justicia y el estado de derecho en las Américas (OEA/ Ser.L/V/II, Doc. 44, 05/12/ 2013, p. 93), sobre la importancia de las mayorías calificadas como salvaguarda para reforzar los procedimientos de selección de magistrados, pues evitan las mayorías partidarias e incrementan la transparencia, resultando más evidente para el público que elige a los candidatos basándose en el mérito y las capacidades personales. La CSJA no duda en recurrir a la intención del constituyente para interpretar que esta forma de elaborar este listado «soslaya el importante rol que cumplen las mayorías calificadas en la búsqueda de equilibrios y consensos en los órganos colegiados y colisiona con la intención del constituyente de 1994 que, al definir la composición del CM, procuró evitar que en el seno de ese cuerpo pudieran consolidarse posiciones hegemónicas».

Siguiendo a la Corte Interamericana, recuerda «que la provisionalidad no debe significar alteración alguna del régimen de garantías para el buen desempeño del juzgador y la salvaguarda de los propios justiciables [...] y el Estado debe garantizar un procedimiento para el nombramiento de estos últimos [subrogantes] sobre la base de parámetros básicos de objetividad y razonabilidad que aseguren el ejercicio independiente de su cargo» (caso Apitz Barbera y otros, Corte Primera de lo Contencioso Administrativo $v$. Venezuela, sentencia 05/09/2008, párr..43; Caso Reverón Trujillo $v$. Venezuela, sentencia 30/6/2009, párr. 114; Caso Chocrón Chocrón v. Venezuela, sentencia 1/7/2011, párr. 103).

En suma, considera que la forma en que se elabora el listado de abogados y secretarios judiciales como futuros posibles jueces subrogantes hace que «la Administración de Justicia quede en manos de personas que han sido seleccionadas por mayorías simples, distintas a las exigidas para los jueces permanentes y que, además, ni siquiera han atravesado un concurso para demostrar sus condiciones y aptitud para el ejercicio del cargo» lo que lesiona el umbral de la garantía de la independencia judicial.

Finalmente, la CSJA descalifica la posibilidad que el CM pueda designar jueces subrogantes en juzgados nuevos cuya cobertura se hallara pendiente de seguir el trámite de selección. Situación que, advierte, se agrava cuando casi un cuarto de los juzgados federales se encuentran vacantes en forma per- 
manente, señalando la CSJA que ello es «imputable en gran medida a la demora en los procesos de selección y designación de magistrados a cargo del CM, del Senado y del Poder Ejecutivo de la nación». Por tanto, una situación que debería ser excepcional se convierte en regla en el sistema de reemplazos, «desnaturalizándose la esencia y la razón de ser de la figura del subrogante», generando «una justicia de excepción en la que no rige la garantía del juez natural ni de la independencia judicial». Como conclusión —aquí lo notable del caso- - la CSJA declara la inconstitucionalidad de la totalidad de un texto legal, de toda la ley 27145.

Y como corolario, ante la invalidación del texto legal completo y el vacío legal consecuente, procede a dictar pautas para la cobertura de los cargos vacantes, haciendo revivir algunas disposiciones de las leyes anteriores que habían sido derogadas por la ley invalidada, dando ultractividad al art. 1.a y art. 2, primer párrafo, de la Ley 26376 y art. 1 de ley 26 372, en cuanto solo admite como jueces subrogantes a quienes revistan la condición de jueces en otras jurisdicciones, o a jueces jubilados (art. 16 ley 24 018) designados por sorteo, porque entiende que "para resguardar adecuadamente la garantía de independencia del Poder Judicial, se deben agotar todas las posibilidades para que las vacantes sean cubiertas, en primer término, por quienes accedieron a un cargo en la magistratura de acuerdo con el especial mecanismo establecido en la Constitución Nacional».

La CSJA, sirviéndose de la jurisprudencia de la Corte Interamericana de Derechos Humanos, «que debe servir de guía para la interpretación de los preceptos convencionales de orden internacional» (sic), hace hincapié en que el principio de independencia judicial constituye uno de los pilares básicos de las garantías del debido proceso, y en la importancia de la inamovilidad para el correcto ejercicio de su función, pues los jueces gozan de la garantía de estabilidad y permanencia como forma de asegurar su independencia.

\title{
2. LA CORTE FORTALECE EL ROL DE TRIBUNAL CONSTITUCIONAL
}

\author{
Caso Anadon, Tomás Salvador v. Comisión Nacional de \\ Comunicaciones, sentencia de despido. La CSJA reduce su rol como \\ tribunal de apelación ordinaria. Fallos 338-2: 724
}

La función jurisdiccional en Argentina se divide en competencia federal (asuntos que el Estado federal es parte) y competencia ordinaria (asuntos civiles, penales, laborales). Esta última competencia es ejercida por los tribunales ordinarios de cada provincia, pero en la capital federal está a cargo de los tribunales «nacionales», compuesto por jueces de primera instancia, y las cámaras de apelaciones de segunda instancia cuyas sentencias pueden ser revisadas 
por recurso de apelación ordinario ante la propia Corte Suprema de Justicia argentina, que actúa, entonces, como tribunal de tercera instancia en juicios comunes donde no hay una cuestión federal o constitucional en debate. A fin de no colapsar la CSJA con causas ordinarias de poca monta, la ley restringió a aquellos asuntos con un determinado monto (casos que superen los 680000 euros) la posibilidad de apelación ordinaria ante la CSJA de sentencias definitivas de cámaras nacionales de apelaciones en que el Estado nacional sea directa o indirectamente parte. En suma, este asunto dio ocasión motivo a la CSJA para replantear su rol como tribunal de tercera instancia ordinaria en ciertos juicios comunes en que el Estado nacional es demandado pecuniariamente.

Esta sentencia se halla en línea con otras precedentes por las cuales la CSJA busca reafirmar y fortalecer su rol como tribunal constitucional, desprendiéndose de aquellos asuntos sin valor, sustancia o trascendencia constitucional (caso Itzkovich, Fallos: 328: 566; caso Pedraza, 2014).

Es elocuente la CSJA en el encuadre conceptual de este asunto: "La efectividad del principio de supremacía constitucional — consagrado en el art. 31 de la Constitución - demanda un régimen de control de la constitucionalidad de las leyes, normas y actos de los gobernantes, que en nuestro sistema es judicial y difuso, y que está depositado en todos y cada uno de los jueces. A su vez, la eficacia y uniformidad de ese control requiere la existencia de un tribunal especialmente encargado de revisar las decisiones dictadas al respecto, órgano que en el régimen de la Constitución no es otro que la Corte Suprema de Justicia de la Nación» para poner el énfasis en «su primera y más importante función, concerniente a la interpretación de cuestiones federales, en particular las referidas a la vigencia de los derechos fundamentales y el sistema representativo, republicano y federal».

Echa mano del estándar de razonabilidad para analizar la competencia reglamentaria del Congreso en esta materia por una ley de 1902 (Ley 4055), para reflexionar que «a 113 años del debate parlamentario sobre la cuestión, el análisis de proporcionalidad deberá necesariamente considerar si la tercera instancia ordinaria pudo haber devenido — con el transcurso del tiempo y el cambio de las circunstancias objetivas - contraria a la función que la Constitución le encomienda a la Corte». Para ello advierte que «la razonabilidad de la norma cuya validez constitucional se cuestiona debe evaluarse a la luz de las nuevas y diversas problemáticas que durante los últimos años han sido traídas ante los estrados de este Tribunal».

Luego de hacer un racconto, por un lado, del incremento de asuntos de naturaleza social y colectiva que han ocupado la atención de la Corte y, por otro, la progresiva consolidación y reducción del rol de la CSJA como tribunal constitucional que la legislación le fue atribuyendo, considera que «la vigencia del recurso ordinario de apelación debe evaluarse a la luz de la interpretación 
contemporánea de las funciones de esta Corte que surge tanto de su jurisprudencia como de la legislación dictada por el Congreso de la nación, y teniendo en especial consideración la necesidad de fortalecer los mecanismos de control de constitucionalidad que aseguren la supremacía de la Constitución nacional con vistas a 'afianzar la justicia'".

Precisamente, este recurso ordinario se halla en contraposición con el criterio de trascendencia constitucional, pues su admisibilidad se basa simplemente en el valor económico del pleito, en tanto permite someter casos al Tribunal cimero sin acreditar una cuestión de derecho federal. En consecuencia, el recurso ordinario se apoya en un criterio económico ajeno al rol constitucional asignado a la Corte Suprema. Por ello, interpreta con acierto que deviene en insostenible la distinción de causas según un parámetro cuantitativo y mecánico, pues el valor económico del litigio no es un medio de por sí idóneo para evaluar la afectación de los valores de nuestra Carta Fundamental porque la competencia de la Corte debe regirse por criterios que hagan a la salvaguarda de principios constitucionales. Esto convierte en irrazonable la distinción que la norma establece para el acceso a la revisión ordinaria entre los procesos patrimoniales de cierto monto en los que una de las partes es la nación, y los litigios en las que no se dan esos extremos, porque este parámetro cuantitativo se convierte de un privilegio para unos casos y restricción total para otros respecto de posibilidades concretas de actuación en una tercera instancia ordinaria, porque, en definitiva, la Corte Suprema debe fallar todos los asuntos en que pueda estar comprometido algún principio constitucional, sin que estas cuestiones se midan por la cantidad de dinero que puedan importar, porque — reflexiona la CSJA — un caso en el que esté en juego una suma muy elevada puede depender de una norma de derecho común, mientras que una cuestión de unos pocos centavos, puede afectar todo el sistema de la propiedad y quizás todo el sistema constitucional.

Concluye, entonces, que en la actualidad esta vía de apelación ordinaria se contrapone a la misión específica del Tribunal, por lo que procede a declarar la inconstitucionalidad de la previsión legal que lo autoriza.

\section{PRIMARIAS ABIERTAS SIMULTÁNEAS OBLIGATORIAS (PASO)}

(Alianza UNEN-CF. E.N. - M. del Interior. Amparo). Fallos 338-1: 628

Por primera vez en Argentina se aplicó un sistema novedoso de elección de candidatura federales en primarias abiertas simultáneas y obligatorias (PASO). Consiste en que los candidatos a presidente y vicepresidente de la nación, así como los senadores y diputados nacionales de cada provincia (primarias), que representarán a cada partido o alianza electoral, surgen de una elección previa a la definitiva con el voto directo de todos ciudadanos afiliados 
o no a un partido político (abierta), que deben concurrir a votar (obligatoriamente) a comicios celebrados el mismo día (simultánemante). Es decir, que todos los partidos y alianzas electorales se encuentran constreñidos a presentar como candidatos para las elecciones nacionales a presidente y vicepresidente de la nación, a diputados nacionales de los 24 distritos electorales y a senadores nacionales de las ocho provincias que renuevan en cada ciclo. O sea, el elector ese día tiene la obligación de concurrir al comicio, quien con un solo voto manifiesta una doble intención que anticipa el resultado, pues al elegir a un precandidato a presidente y vicepresidente y a un listado de precandidatos nacionales a diputados y senadores (donde correspondiera) de entre las distintas listas presentadas por cada partido o alianza, por un lado define quiénes serán los candidato de ese partido o alianza y, a la vez, por otro lado quedan expuestas y anticipan las preferencias por el partido o alianza de esas precandidaturas.

Las PASO tuvieron lugar el domingo 11 de agosto de 2015 de donde surgieron los candidatos definitivos a presidente y vicepresidente, diputados y senadores nacionales de cada partido o alianza electoral nacional.

El caso en cuestión trata sobre el aporte estatal para la impresión de las boletas de sufragio de los precandidatos de cada partido o alianza. La Dirección Nacional Electoral, oficina administrativa encargada de administrar los recursos para los comicios, denegó a una alianza electoral los fondos económicos para la impresión de las boletas de todas las listas de precandidatos pertenecientes a dicha alianza con el argumento de que la ley solo autoriza un aporte único para la impresión de boletas por partido o alianza.

Esta alianza electoral presentó un amparo reclamando estos fondos para subvenir la impresión de las boletas electorales de todas las listas de precandidatos de integran esa alianza. El juez de primera instancia lo concedió, lo que fue ratificado por la Cámara Electoral Nacional. Sin embargo, el Estado nacional recurrió por recurso extraordinario ante la CSJA.

La CSJA teniendo en cuenta que «el entendimiento de una ley debe atenerse a los fines que la inspiran, y debe preferirse siempre la interpretación que los favorezca y no la que los dificulte», concluye que "una adecuada interpretación de la norma electoral exige privilegiar, entre las posibles, la que respete con mayor fidelidad la eficacia de la libre manifestación de la voluntad política antes que priorizar una solución que pueda evitar conocer la expresión genuina del cuerpo electoral». Sobre la base del art. 37 CA que "garantiza el pleno ejercicio de los derechos políticos, con arreglo al principio de la soberanía popular y de las leyes que se dicten en consecuencia» y consagra el voto «universal, igual, secreto y obligatorio», cita a la Corte Interamericana que señala en el caso Castañeda Gutman $v$. Estados Unidos Mexicanos (sentencia 06/08/2008) que «el art. 23 de la Convención no solo establece que sus ti- 
tulares deben gozar de derechos, sino que agrega el término 'oportunidades'. Esto último implica la obligación de garantizar con medidas positivas que toda persona que formalmente sea titular de derechos políticos tenga la oportunidad real para ejercerlos» (párr. 145), lo que lleva a la CSJA a concluir que «la boleta electoral exterioriza la voluntad del elector y resulta en consecuencia indispensable para ejercer el derecho al sufragio en el marco de un proceso eleccionario que establece a las primarias abiertas, simultáneas y obligatorias [...] dentro del marco constitucional reseñado, que en la organización de los comicios obliga al Estado a garantizar la certeza y seguridad de que el voto pueda ser materialmente emitido a través de la boleta».

En resumen, la norma debe ser interpretada en el sentido de que habilita a las agrupaciones políticas a percibir un importe para la impresión de una boleta por elector para cada lista de precandidatos que oficialicen para participar en las elecciones primarias porque así se resguarda el derecho del elector y resulta coherente con el fin de garantizar la efectiva vigencia del principio democrático de la representatividad popular y, específicamente, con los propósitos perseguidos por la ley de las primarias abiertas, simultáneas y obligatorias, de fortalecer y profundizar la participación ciudadana en la selección de los candidatos de cada agrupación política para las elecciones generales, y de limitar la financiación privada para garantizar la igualdad entre las diferentes agrupaciones.

\section{CONFLICTOS CON ESTADOS PROVINCIALES}

\section{COPARTICIPACIÓN IMPOSITIVA FEDERAL}

Caso Provincia de Santa Fe v. Estado nacional, sentencia de acción declarativa de inconstitucionalidad. Fallos 338-2: 1362

Quizás la sentencia de mayor transcendencia constitucional del año 2015 fue aquella que ordenó la devolución del $15 \%$ de los impuestos retenidos indebidamente por el Gobierno nacional a tres provincias que reclamaron judicialmente la invalidez de esta detracción y el reembolso de todo lo retenido?.

9 La provincia de San Luis interpuso una acción análoga que obtuvo idéntica sentencia favorable de la CSJA (CSJ 191/2009 (45-S)/CS1, caso provincia de San Luis v. Estado Nacional, sentencia de acción declarativa de inconstitucionalidad y cobro de pesos). Igual demanda interpuso la provincia de Córdoba, la que si bien no tiene sentencia aún, por tratarse de un asunto análogo obtuvo una medida cautelar de la CSJA de cese 
La CSJA tiene competencia originaria y exclusiva en juicios que entablen las provincias en su condición de Estado federado contra el Gobierno federal (art. 117 CA), razón por la cual el juicio se interpuso directamente ante el Supremo Tribunal como acción declarativa de inconstitucionalidad.

La cuestión gira en torno a una retención que realizó el Estado nacional sobre el porcentaje que le correspondía percibir a la provincia de Santa Fe en concepto de "coparticipación federal» de impuestos. La llamada coparticipación federal consiste en un sistema de recaudación de un grupo de impuestos que se ocupa de hacerlo el Estado federal quien, luego de percibirlos, debe girar automáticamente a cada provincia un determinado porcentaje de esa masa integrada por un conjunto de impuestos sobre los que las provincias tienen derecho propio de imposición pero decidieron no establecerlos a cambio de que los recaude la nación y los distribuya. Este compromiso recíproco se concreta a través de una ley convenio para la cual la Constitución fija un mecanismo singular: debe haber un acuerdo previo entre el Estado federal y cada estado provincial, acuerdo que se convierte en una ley dictada por la nación, que luego debe recibir la adhesión de cada una de las provincias para ser efectiva respecto de esa provincia. Si alguna provincia no presta ese acuerdo, el régimen no le resulta aplicable a ella.

El caso particular consiste en que el Estado nacional por una ley (que no fue precedida por un acuerdo nación-provincias) decidió detraer del porcentaje de coparticipación que le correspondía a la provincia de Santa Fe, un porcentaje del $15 \%$ destinado a financiar gastos de origen previsional. La provincia de Santa Fe en 1993 había aceptado esta deducción. Luego, este convenio fue sucesivamente prorrogado en 1995 y, finalmente, en el año 2000 por cinco años más, recibiendo en cada caso la pertinente y expresa adhesión por ley provincial en cada caso. El último acto de adhesión había expirado en el año 2005. Sin embargo, el Estado nacional por una ley del año 2006 decidió unilateralmente prorrogar la retención sin contar con la previa adhesión ni consentimiento posterior por ley del estado provincial. Desde entonces

de la retención (CSJ 786/2013 (49-C) /CS1, provincia de Córdoba $v$. Estado nacional y otro, sentencia de medida cautelar»). Por añadidura, la provincia de Santa Fe inició otro juicio contra el Estado nacional por retención unilateral de un porcentaje de la masa coparticipable, sin el consentimiento de la provincia, para subvenir gastos del ente recaudador nacional (Dirección General Impositiva): caso provincia de Santa Fe $v$. Estado Nacional, sentencia de acción declarativa de inconstitucionalidad (Expte. 539/2009 (45-S) ORIGINARIO), que en la misma fecha la CSJA declaró inconstitucional por el Decreto 1399/2001 del Poder Ejecutivo que disponía esa detracción (Fallos 338-2:1400). Id. San Luis (CSJ 1039/2008 (44-S)/CS1, provincia de San Luis $v$. Estado Nacional y otra sentencia sobre cobro de pesos). 
continuó reteniendo un 15\% sobre el porcentaje de coparticipación que le correspondía a esa provincia.

Este fallo resulta constitucionalmente muy valioso porque la CSJA se ocupa de interpretar el sistema de coparticipación fiscal establecido por la reforma constitucional de 1994.

Debe señalarse que por mandato constitucional se encuentra pendiente de sancionarse un nuevo convenio de coparticipación federal conforme lo establece la disposición transitoria sexta: No obstante, esta omisión fue cubierta por sucesivos pactos fiscales entre el Estado nacional y las provincias (1992, 1993, 1999, 2000), ratificados por sus respectivas leyes nacionales y provinciales (leyes convenios), que se convirtió en la vía habitual para estructurar ese espacio institucional de concertación federal requerido por la Constitución, desde donde se flexibilizó, en un contexto de participación igualitaria, la distribución de la recaudación coparticipable.

Para la Corte «esos acuerdos de voluntad que constituyen manifestaciones positivas del llamado federalismo de concertación, inspirado en la búsqueda de un régimen concurrente en el cual las potestades provinciales y nacionales se unen en el objetivo superior de lograr una política uniforme en beneficio de los intereses del Estado nacional y de las provincias».

La consecuencia natural, entonces, es que «dichos pactos fiscales, como las demás creaciones legales del federalismo de concertación, configuran el derecho intrafederal y se incorporan una vez ratificados por las legislaturas al derecho público interno de cada Estado provincial, aunque con la diversa jerarquía que les otorga su condición de ser expresión de la voluntad común de los órganos superiores de nuestra organización constitucional: nación y provincias. Esa gestación institucional los ubica con un rango normativo específico dentro del derecho federal. Prueba de su categoría singular es que no es posible su derogación unilateral por cualquiera de las partes».

La trascendencia de este fallo reside en la definición de un tipo de ley especial: las leyes convenio, que tienen un origen convencional que les confiere una posición superior en el sistema de fuentes. En efecto, para el CSJA «esa jerarquía superior que cabe reconocerle a los acuerdos intrafederales $\mathrm{y}$ a las leyes convenio es inherente a su propia naturaleza contractual en la que concurren las voluntades de los órganos superiores de la Constitución en aras de alcanzar objetivos comunes. Constituyen, entonces, la máxima expresión del federalismo de concertación, condición de la que se desprende su virtualidad para modificar — siempre en el marco de la Ley Fundamental- las relaciones interjurisdiccionales y recíprocas entre la nación y las provincias». Esta naturaleza convencional, por tanto, por ser «la esencia misma del derecho intrafederal, impone concluir que las leyes convenio y 
los pactos que lo componen no se encuentran en una esfera de disponibilidad individual de las partes, y solo pueden ser modificados por otro acuerdo posterior de la misma naturaleza, debidamente ratificado por leyes emanadas de las jurisdicciones intervinientes». En consecuencia, "no es admisible que un sistema jurídico interestatal, que se expresa mediante la suscripción de pactos federales (o la sanción de leyes convenio), y tantas leyes aprobatorias o de adhesión como estados parte, sea reglamentada por la nación, que no es sino uno de esos estados».

Sin embargo, el Estado nacional subrepticiamente, al sancionar la ley de presupuesto del ejercicio 2006, introdujo un artículo por el que prorroga unilateralmente esta retención del $15 \%$ a todas las provincias con igual destino. En el fondo surge una nueva cuestión porque esto implicaba una trasformación en la naturaleza de esa retención, que ahora quedaba bajo el concepto de «asignación específica» regulada en el inc. 3 del art. 75 CA. La CSJA se ocupa ahora, por tanto, de esclarecer este punto, interpretando esta disposición constitucional en el sentido que de ella «se extrae que lo que el legislador puede detraer, en todo o en parte, cumpliendo con las exigencias de la ley, son los impuestos directos o indirectos que en cada caso individualice, pero esa detracción no la debe ejercer porque la cláusula constitucional no lo habilita para ello sobre la totalidad o una porción de la masa de manera indefinida [...]. Las asignaciones específicas solo pueden ser establecidas por el Congreso Nacional sobre una parte o el total de la recaudación de impuestos indirectos o directos en particular, por tiempo determinado y mediante la sanción de una ley especial con las referidas mayorías agravadas de ambas Cámaras, y que esta es la única y excepcional facultad con la que cuenta la nación para afectar los impuestos que integran la masa coparticipable, sin necesidad de contar con un pacto o la previa conformidad de las provincias y de la ciudad autónoma de Buenos Aires».

Se introduce en el debate un asunto interesante: si el voto afirmativo de los diputados y senadores de la provincia Santa Fe puede ser tenido como expresión de conformidad del estado provincial de procedencia. La CSJA lo niega porque: «No son ellos quienes revisten la condición de órganos superiores de nuestra organización constitucional, ni sus votos pueden traducirse en la expresión de voluntad del estado provincial, pues en el marco del federalismo de concertación el representante natural de la provincia es su gobernador. No le corresponde entonces al Congreso legislar en nombre de una provincia, suplantando la representación de esa soberanía» pero, además, añade que «la conformidad referida no sella el resultado de la pretensión, cuando el ejercicio de la facultad del Congreso de la nación no se ajusta a lo que la Constitución nacional impone». 


\section{CONTROL DE REFORMA CONSTITUCIONAL PROVINCIAL}

\section{Colegio de Abogados de Tucumán v. Honorable Convención Constituyente de Tucumán y otro. Fallos 338-1: 249}

Llega a resolución de la CSJA el cuestionamiento presentado por el Colegio de Abogados del estado provincial de Tucumán contra tres disposiciones introducidas en la Constitución provincial por la Convención Reformadora de 2006. El asunto se inicia a través de una acción declarativa de inconstitucionalidad, prevista en el Código Procesal Constitucional de Tucumán, presentada ante un tribunal de primera instancia, cuya sentencia fue luego revisada por recurso de casación por el Superior Tribunal de Justicia de este estado federado. La decisión final de este último tribunal fue objeto de recurso extraordinario por ante la CSJA, que denegado por el tribunal de origen, dio lugar a un recurso directo de queja ante el Tribunal Superior Federal, que rechazó la queja confirmando la sentencia del tribunal provincial. Básicamente, el rechazo se basa en que el asunto no reviste cuestión federal suficiente, es decir, no involucra asuntos federales que justifiquen la intervención de la CSJA.

Sin embargo, resulta interesante consignar tres puntos de notable trascendencia expresados por la CSJA: a) sobre el valor que para el sistema democrático tiene la observancia por la mayoría de ciertas formalidades en la formación de la voluntad democrática; b) sobre las facultades de control judicial sobre reformas constitucionales provinciales y, c) sobre la capacidad de configuración constitucional que tienen los estados provinciales para configurar su propia organización estatal a través de su constitución.

Sobre lo primero señalará «que la Constitución nacional no admite la validez de una voluntad popular expresada sin respetar los principios del Estado de derecho ni permite que las mayorías puedan derogar los principios fundamentales sobre los que se basa la organización republicana del poder y la protección de los ciudadanos. El escrutinio judicial de los procedimientos resulta esencial para robustecer las prácticas democráticas. Estas normas constituyen un presupuesto para que la decisión mayoritaria sea válida».

En consecuencia, la CSJA recuerda, en relación con el segundo tema, que «la procedencia del control judicial sobre las convenciones reformadoras, cabe remitir a la jurisprudencia del Tribunal que ha definido el carácter justiciable de la regularidad del proceso de reforma de las constituciones provinciales y ha marcado los límites que sujetan su actuación con el fin de no transgredir el principio republicano de la división de poderes aplicable a las provincias en virtud del art. 5 de la Constitución nacional (Fallos: 335:2360, y sus citas)», para seguidamente reafirmar que «las instituciones reflejadas en el estatuto del poder constitucional constituyen un sistema de gobierno cuya tutela debe estar protegida de un modo acorde a su especial y trascendente naturaleza. En 
la Constitución originaria dicha protección descansaba en el funcionamiento del sistema democrático, y en la convicción de que ello era suficiente. La experiencia histórica ha demostrado que también es necesaria la intervención de los poderes judiciales estableciendo límites a través del control de constitucionalidad de las leyes, lo que fue expresado claramente por esta Corte (CSJ 369/2013 (49-R), Jorge Gabriel Rizzo, fallada el 18 de junio de 2013).

Finalmente, la CSJA se ocupa de subrayar la capacidad de configuración institucional que goza cada provincia, «si bien el art. 5 citado declara la unidad de los argentinos en torno del ideal republicano, lo hace con arreglo a la diversidad proveniente de la organización federal en cuanto encierra un reconocimiento y respeto hacia las identidades de cada provincia, que encuentra su campo de realización dentro del ámbito comprendido por los poderes no delegados al Gobierno de la nación (arts. 121 y 122 CA) y también en el de la adecuación de sus instituciones a los requerimientos del art. 5» y recurre como argumento de autoridad a Joaquín V. González, para quien la necesidad de armonía entre los estados particulares y el Estado nacional «no exige, ni puede exigir que sean idénticas, una copia literal o mecánica, ni una reproducción más o menos exacta e igual de aquella. Porque la constitución de una provincia es un código que condensa, ordena y da fuerza imperativa a todo el derecho natural que la comunidad social posee para gobernarse, a toda la suma de soberanía inherente, no cedida para los propósitos más amplios y extensos de fundar la nación. Luego, dentro del molde jurídico del código de derechos y poderes de esta, cabe la más grande variedad, toda la que pueda nacer de la diversidad de caracteres físicos, sociales e históricos de cada región o provincia, o de sus particulares anhelos o aptitudes colectivos (Manual de la Constitución argentina, págs. 648-649, reproducido por el Tribunal en los Fallos: 311:460, considerando 19)», para reafirmar «la autonomía con que cuentan los estados federados en los términos señalados para reglar lo concerniente al procedimiento jurídico político por el cual reforman sus constituciones y para establecer las autoridades que participarán en el nombramiento de sus magistrados judiciales».

De este modo, finalmente, rechaza la intervención de la máxima autoridad judicial federal para controlar esta reforma constitucional provincial porque entiende que «el corazón del conflicto normativo resuelto en el fallo apelado y cuya revisión se promueve en el recurso extraordinario, remite exclusivamente al examen de compatibilidad entre disposiciones que — como la ley que declaró la necesidad de reforma de la constitución y las disposiciones sancionadas por la convención - son de derecho público local, cuyo resultado no puede ser fundadamente alterado por la interpretación que se lleve a cabo de las cláusulas de la Constitución nacional que se invocan como vulneradas, circunstancia que demuestra la improcedencia de que tome intervención el Gobierno Federal a través del órgano que es titular del Departamento Judicial». 